11/14/94

for publication in Design for Manufacturability and Manufacture of Ceramic

Components, Transactions of the American Ceramic Society, The American

Ceramic Society, Westerville, OH (1995)

\title{
MANUFACTURING TAILORED PROPERTY CERAMIC COMPOSITES
}

Kevin G. Ewsuk

Ceramic Processing Science

Department 1841 - MS 1349

Sandia National Laboratories

Albuquerque, NM 87185-1349

\section{Larry W. Harrison}

Central Research and Development Dept.

Experimental Station - E262

E. I. du Pont de Nemours \& Co., Inc.

Wilmington, DE 19898-0262

\begin{abstract}
Composite materials are desirable for many advanced engineering applications where the properties of a single phase material cannot meet all of the service requirements; however, existing process technology has limited the development and commercialization of composites. Lack of reproducible sintering to high density is one of the major obstacles to commercializing ceramic composites. Final-stage, non-reactive liquid phase sintering (NLPS) theory provides metrics for sinterability that can be used as guidelines to design and manufacture dense ceramic-filled-glass ( $\mathrm{CFG}$ ) composites. Additionally, within the constraints defined by the NLPS theory, sum-property models can be used to predict CFG composite properties, and to design composites with properties tailored to specific applications. By integrating composite process models with composite property models, processable, application-tailored $\mathrm{CFG}$ composites for microelectronics packaging have been designed and fabricated.
\end{abstract}

\section{INTRODUCTION}

Technology evolution and maturation is very much dependent on advanced materials and materials processing [1]. Advances in microelectronics, for instance, hinge on the development of new materials with unique combinations of mechanical, thermal, and electrical properties. For example, an ideal ceramic packaging material is an inexpensive, low dielectric constant, low dielectric loss, high thermal conductivity ceramic that has a thermal expansion match to the semiconductor chip (e.g., Si), and can be co-fired with high electrical conductivity metallization such as $\mathrm{Cu}$ (Table 1) [2].

\section{DISCLAIMER}

This report was prepared as an account of work sponsored by an agency of the United States Government. Neither the United States Government nor any agency thereof, nor any of their employees, makes any warranty, express or implied, or assumes any legal liability or responsibility for the accuracy, completeness, or usefulness of any information, apparatus, product, or process disclosed, or represents that its use would not infringe privately owned rights. Reference herein to any specific commercial product, process, or service by trade name, trademark, manufacturer, or otherwise does not necessarily constitute or imply its endorsement, recommendation, or favoring by the United States Government or any agency thereof. The views and opinions of authors expressed herein do not necessarily state or reflect those of the United States Government or any agency thereof.

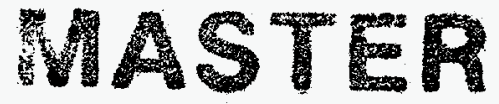

DISTRIBUTION OF THIS DE.CBMENT IS UNHMITET

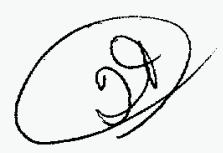


Table 1. Desired Microelectronics Package Characteristics

\begin{tabular}{|l|l|}
\hline \multicolumn{1}{|c|}{ Desired Characteristic } & \multicolumn{1}{c|}{ How Achieved } \\
\hline $\begin{array}{l}\text { Low Propagation Delay } \\
\text { (High Speed) }\end{array}$ & $\begin{array}{l}\text { - Low Dielectric Constant Substrate } \\
\text { - High Package Density }\end{array}$ \\
\hline High Circuit Count (Larger Chip) & $\begin{array}{l}\text { - Coefficient of Thermal Expansion Match } \\
\text { of Semiconductor Chip and Substrate } \\
\text { - Large Multichip Substrate }\end{array}$ \\
\hline Uniform Power Distribution & - High Electrical Conductivity Metallization \\
\hline Uniform, Rapid Heat Removal & $\begin{array}{l}\text { - High Thermal Conductivity Substrate } \\
\text { - High Thermal Conductivity Heat Sinks }\end{array}$ \\
\hline
\end{tabular}

An examination of the properties of some common ceramic packaging materials (Table 2) reveals that, while all of the materials have some of the desired properties, no one has all of the desired characteristics [3]. $\mathrm{Al}_{2} \mathrm{O}_{3}$, which is inexpensive, is the most widely used ceramic packaging material. $\mathrm{BeO}$ and $\mathrm{AIN}$ have better thermal properties than $\mathrm{Al}_{2} \mathrm{O}_{3}$, but at considerably greater expense. $\mathrm{AlN}$ has a good thermal expansion match to $\mathrm{Si}$, but requires a high firing temperature. Of the ceramic materials listed in Table 2, the glass+ceramic composites tend to satisfy many of the desired characteristics of a microelectronics package. The goal now becomes to optimize the desirable characteristics, and minimize undesirable ones.

Table 2. Ceramic Packaging Materials

\begin{tabular}{|c|c|c|c|c|}
\hline Property & $\begin{array}{c}96 \% \\
\mathrm{Al}_{2} \mathrm{O}_{3} \\
\end{array}$ & $\mathbf{B e O}$ & AIN & $\begin{array}{l}\text { Glass + } \\
\text { Ceramic }\end{array}$ \\
\hline $\begin{array}{l}\text { Coefficient of Thermal } \\
\text { Expansion }\left(\mu \mathrm{m} / \mathrm{m} /{ }^{\circ} \mathrm{C}\right) \\
25-200^{\circ} \mathrm{C} \\
25-500^{\circ} \mathrm{C}\end{array}$ & $\begin{array}{l}6.0 \\
7.4\end{array}$ & $\begin{array}{l}6.4 \\
7.7\end{array}$ & 4.3 & $3-7$ \\
\hline Thermal Conductivity $(\mathrm{W} / \mathrm{m} \cdot \mathrm{K})$ & 24.7 & 280 & $70-220$ & $1-4$ \\
\hline Modulus of Rupture (MPa) & 358 & 280 & $280-350$ & $100-200$ \\
\hline Youngs Modulus (M]Pa) & 303 & 345 & $300-340$ & \\
\hline Dielectric Constant $(\mathbf{a} 1 \mathrm{MHz}$ & 9.0 & 6.6 & $8.5-9.0$ & $4-8$ \\
\hline Dielectric Loss@1 MHz & 0.0001 & 0.0003 & $0.0001-0.0002$ & $>0.002$ \\
\hline
\end{tabular}




\section{DISCLAIMER}

Portions of this document may be illegible in electronic image products. Images are produced from the best available original document. 
Through careful control of composition and microstructure, it is possible to design composite materials with unique combinations of properties tailored to specific applications. Additionally, composites can be designed for improved processability. For example, the addition of a low-temperature deforming glass to a refractory ceramic such as alumina promotes faster densification and more uniform microstructure development at lower sintering temperatures. The advantages of sintering with a liquid phase, which have long been recognized in both powder metallurgy [4-6] and ceramic processing [7-9], are now being applied to manufacture ceramic-filled-glass (CFG) composites for microelectronics packaging [10-14].

CFG composites are appealing as low-temperature sintering substrates that can be co-fired with high electrical conductivity metallization [10-14]. Additionally, by controlling the compositions and concentrations of the glass and ceramic phases of a CFG composites, it is possible to design and fabricate composites with properties tailored to microelectronic packaging needs (e.g., Table 1). There are numerous examples of research and development efforts to design and fabricate tailored-property, CFG composites for microelectronics packaging, including efforts to optimize dielectric constant [8,15-16], thermal conductivity [16-18], and coefficient of thermal expansion $[8,19]$.

In general, previous efforts to design and fabricate tailored-property $\mathrm{CFG}$ composites have focused on identifying and selecting glass and ceramic precursors with desirable properties, and combining them in the prescribed proportions (e.g., as determined empirically or from simple mixing model predictions) to optimize a given property in the resultant composite. While this approach has been successful, it is unnecessarily limiting. That is, focusing on optimizing a single property ignores one of the greatest advantages of composites; the potential to optimize multiple physical properties simultaneously.

This paper will demonstrate how a model for CFG composite densification can be considered simultaneously with simple mixing models for predicting composite dielectric constant, coefficient of thermal expansion, and thermal conductivity to optimize the processing and properties of CFG composite dielectrics for microelectronics packaging.

\section{CERAMIC-FILLED-GLASS (CFG) COMPOSITE SINTERING}

Low-temperature sintering CFG composites densify by a combination of glass redistribution, grain rearrangement, and viscous flow in a three-stage process 
described as non-reactive liquid-phase sintering (NLPS) [20-22]. As in all sintering processes, the driving force for densification during NLPS is the reduction of the free energy of the system. This is accomplished by replacing higher energy solid-solid and solid-vapor interfaces with lower energy liquid-solid and liquid-vapor interfaces during the initial and intermediate stages, and by reducing and minimizing the liquid-vapor interfacial area during the final stage.

Densification during initial-stage glass redistribution and intermediate-stage grain rearrangement occurs rapidly, within the first $\sim 10 \mathrm{~min}$. of sintering [20-21]. Finalstage NLPS is by far slowest stage of sintering, and consequently, it is the critical stage in the development of the microstructure and properties of a CFG composite.

\section{Final Stage Non-Reactive Liquid Phase Sintering (NLPS)}

Final-stage NLPS has been modeled using a viscous sintering theory [23] modified to account for the increased viscosity of a CFG composite dispersion relative to the viscosity of the glass alone [24-26]. Table 3 summarizes the assumptions of the final-stage NLPS model.

Table 3. Assumptions in Modeling Ceramic-Filled-Glass Composite Densification During Final-Stage, Non-Reactive Liquid Phase Sintering

The composite density increases from 92 to $100 \%$ theoretical density.

The glass phase wets the ceramic particles (i.e., the contact angle is $<90^{\circ}$ ).

The CFG composite microstructure is a homogeneous mixture of glasscoated ceramic particles and uniformly-sized, spherical pores.

The glass phase does not react with the ceramic filler to create additional liquid to enhance densification during sintering.

The glass phase does not devitrify and impede densification during sintering.

Liquid-vapor (pore) surface energy provides the driving force for densification.

Densification occurs by pore shrinkage.

All the pores shrink at the same rate.

There is no gas pressure build-up within closed pores to impede densification.

The rate of CFG composite densification during final-stage NLPS, which occurs by viscous flow, is controlled by the viscosity of the CFG composite dispersion, $\eta_{d}$, at the sintering temperature. Based on the work of Eilers [27], the viscosity of 
a glass containing a dispersion of ceramic particles can be approximated from the glass viscosity, $\eta$, at the sintering temperature, and the volume fraction, $\phi$, of ceramic filler in the glass [24];

$$
\eta_{d}=\eta\left(1+\frac{\kappa \phi}{1-\left(\phi / \phi_{\max }\right)}\right)^{2}
$$

where $\kappa$ and $\phi_{\max }$ are constants.

The time, $t$, required to sinter a CFG composite to a given fractional density, $\rho_{t}$, during final-stage NLPS can be approximated by [24-26];

$$
t=2 \frac{r_{0}}{\gamma_{l v}} \eta_{d}\left\{1-\left(1-\frac{\rho_{t}-\rho_{o}}{1-\rho_{o}}\right)^{1 / 3}\right\}
$$

where $r_{o}$ is the pore radius at the onset of final-stage sintering, $\gamma_{1 v}$ is the surface tension of the glass at the sintering temperature, and $\rho_{o}$ is the fractional density at the onset of final-stage sintering (i.e., $\rho_{0}=0.92$ by definition).

To achieve the desired level of densification in a prescribed time for a given pore size and glass surface tension, the viscosity of a CFG composite dispersion, $\eta_{d}$, must be less than or equal to some critical dispersion viscosity, $\eta_{d_{c r i t}}$ [24-26].

$$
\eta_{\text {dcrit }}=\frac{\gamma_{\mathrm{jv}}}{2 \mathrm{r}_{\mathrm{o}}} \frac{\mathrm{t}}{\left\{1-\left(1-\frac{\rho_{\mathrm{t}}-0.92}{0.08}\right)^{1 / 3}\right\}}
$$

The critical dispersion viscosity defined in Equation 3 provides a metric for CFG composite sinterability; specifically, undesirable results (e.g., incomplete densification) will be obtained if $\eta_{d}$ is greater than $\eta_{d}$ crit. 
substituting $\eta_{d_{c r i t}}$ for $\eta_{d}$ in Equation 1 and rearranging, the critical filler concentration, $\phi_{\text {crit }}$, for CFG composite densification during final-stage NLPS can be determined [24-26].

$$
\phi_{\text {crit }}=\frac{\left(\sqrt{\eta_{\text {derit }} / \eta}-1\right) \phi_{\max }}{\left(\sqrt{\eta_{\text {derit }} / \eta}-1\right)+\kappa \phi_{\max }}
$$

The critical filler concentration, $\phi_{\text {crit }}$, defines the exact volume fraction of filler, $\phi$, in glass of viscosity, $\eta$, for which a given density will be achieved in a given time daning final-stage NLPS. Like the critical dispersion viscosity, $\phi_{\text {crit }}$ provides a metric for processing CFG composites. Additionally, the critical filler cancentration provides a design metric for CFG composites; in particular, $\phi$ must be $\leq \phi_{\text {crit }}$ to ensure the desired level of densification during sintering. By plotting arait as a function of $\eta$, detailed sintering maps have been constructed that provide gridelines to design and process CFG composites (Figure 1) [24-26].

The significance of NL.PS theory and sintering maps such as Figure 1 in designing CFG composites is that they define the processing limits, which, in turn, define design constraints. For example a detailed analysis of final-stage NLPS has determined that the maximum ceramic filler concentration that can be incorporated into a CFG composite without sacrificing processability is $\sim 50 \%$ (by volume) [24-26]. The sintering map in Figure 1 shows that high ceramic filler concentrations require: 1) a low viscosity glass (or a higher processing temperatures); 2) small pore sizes (i.e., smaller particle sizes); 3) longer sintering times; and 4) sintering to lower final densities (e.g., sintering to $99 \%$ theoretical density versus $100 \%$ ).

\section{COMPOSITE PROPERTIES}

In the simplest case, only the properties of the individual phases present and their volume fractions need to be considered to model the properties of a composite [28-31]. This is true for sum or additive properties such as density, specific heat and coefficient of thermal expansion [28]. In more complex cases, property 


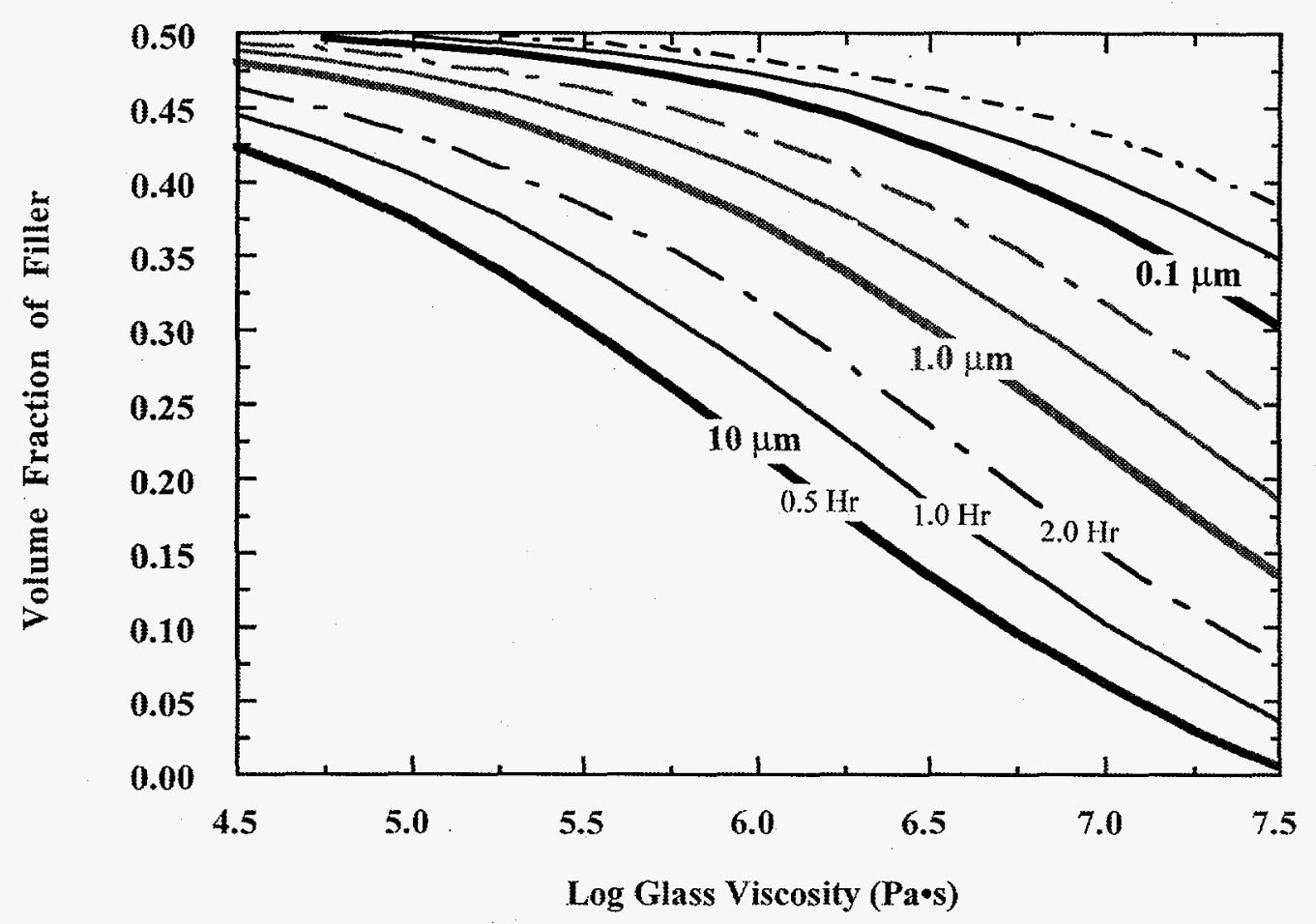

Figure 1. A map of critical filler concentration as a function of glass viscosity for CFG composite densification during final-stage sintering. The curves represent the time to achieve complete densification for a given combination of $r_{o}$, $t$, and $\gamma_{l v}$ (with constants $\kappa=13$, and $\phi_{\max }=0.51$ ). The desired densification is predicted for all conditions of $\phi \leq \phi_{\text {crit }}[25]$.

interactions must also be considered§ (i.e., for combination or product properties) $[28,30]$. Typically, the properties of the phases that comprise the composite, the relative concentrations of the phases present, and the composite microstructure must be considered when modeling sum properties such as dielectric constant, thermal conductivity, and electrical conductivity.

$\S$ for example, the velocity that a wave propagates through a material is determined by the modulus of the material divided by its density, making velocity an interactive property. Strength and hardness are also interactive properties. Interactive properties are more difficult to model than sum properties, and may not be simply related to the properties of the individual phases $[28,30]$ 


\section{Sum Properties}

A two-phase composite can be modeled geometrically as a parallel planar arrangement of alternating phases. The properties of this two-phase composite are determined by the volume-weighted average of the property coefficients, $X_{1}$ and $\mathrm{X}_{2}$, of the two phases, where $f_{1}$ and $f_{2}$ are the volume fractions of phases 1 and 2 , respectively. When the composite property is measured parallel to the planar arrangement (Figure 2), the Parallel Mixing model applies [28-31].

$$
\mathrm{X}_{\text {Comp }}=\mathrm{X}_{1} f_{1}+\mathrm{X}_{2} f_{2}
$$

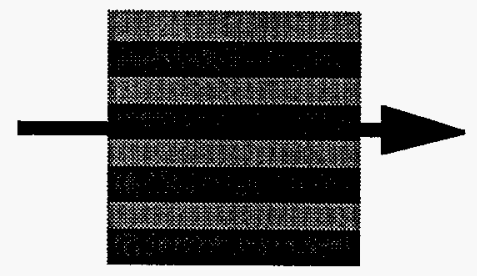

Figure 2. The geometry (cross section) for the Parallel Mixing Model.

When the composite property is measured normal to the planar arrangement (Figure 3), the Series Mixing Model applies [28-31].

$$
\mathrm{X}_{\text {Comp }}=\frac{\mathrm{X}_{1} \mathrm{X}_{2}}{\mathrm{X}_{1} f_{2}+\mathrm{X}_{2} f_{1}}
$$

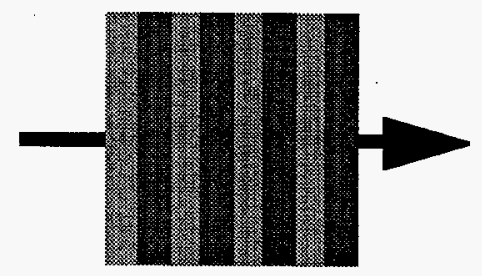

Figure 3. The geometry for the Series Mixing Model

A more realistic model geometry for a two-phase CFG composite, is that of one discontinuous phase, $X_{d}$ (e.g., the ceramic particles), dispersed in a continuous second phase, $X_{m}$ (e.g., the glass matrix). This geometry (Figure 4.) is modeled by the Maxwell Model as [29,31]; 


$$
\mathrm{X}_{\text {Conp }}=\frac{\mathrm{X}_{\mathrm{m}} f_{\mathrm{m}}\left(2 / 3+\mathrm{X}_{\mathrm{d}} / 3 \mathrm{X}_{\mathrm{m}}\right)+\mathrm{X}_{\mathrm{d}} f_{\mathrm{d}}}{f_{\mathrm{m}}\left(2 / 3+\mathrm{X}_{\mathrm{d}} / 3 \mathrm{X}_{\mathrm{m}}\right)+f_{\mathrm{d}}}
$$

Figure 4. The geometry for the Maxwell Mixing Model

As illustrated in Figure 5, the Parallel and Series Mixing Models define the upper and lower property bounds for any sum property of a two-phase composite ${ }^{f}$ $[29,31]$. However, because the geometry of a two-phase composite is typically neither purely parallel nor purely series, its properties are usually intermediate to the parallel and series bounds.

The Maxwell Model predicts properties intermediate to the extremes defined by the Parallel and Series Models (Figure 5). Theoretically the Maxwell Model applies only to infinitely dilute suspensions; however, it has been shown to be applicable for composites with up to $50 \%$ dispersed phase [31].

There are numerous mathematical expressions that model composite properties; however, for simplicity, this paper will focus on the Series, Parallel, and Maxwell Mixing Models. All three models are mathematically tractable, they treat simple geometries, and they make no specific assumptions of scale [31]. Furthermore, the Parallel Mixing Model has been shown to be applicable for composite coefficient of thermal expansion [32], while the Maxwell Model has been applied successfully to describe composite dielectric constant [15,29], and thermal conductivity [18].

$£$ assuming that, other than phases 1 and 2, no other phases (including porosity) are present in the composite body 


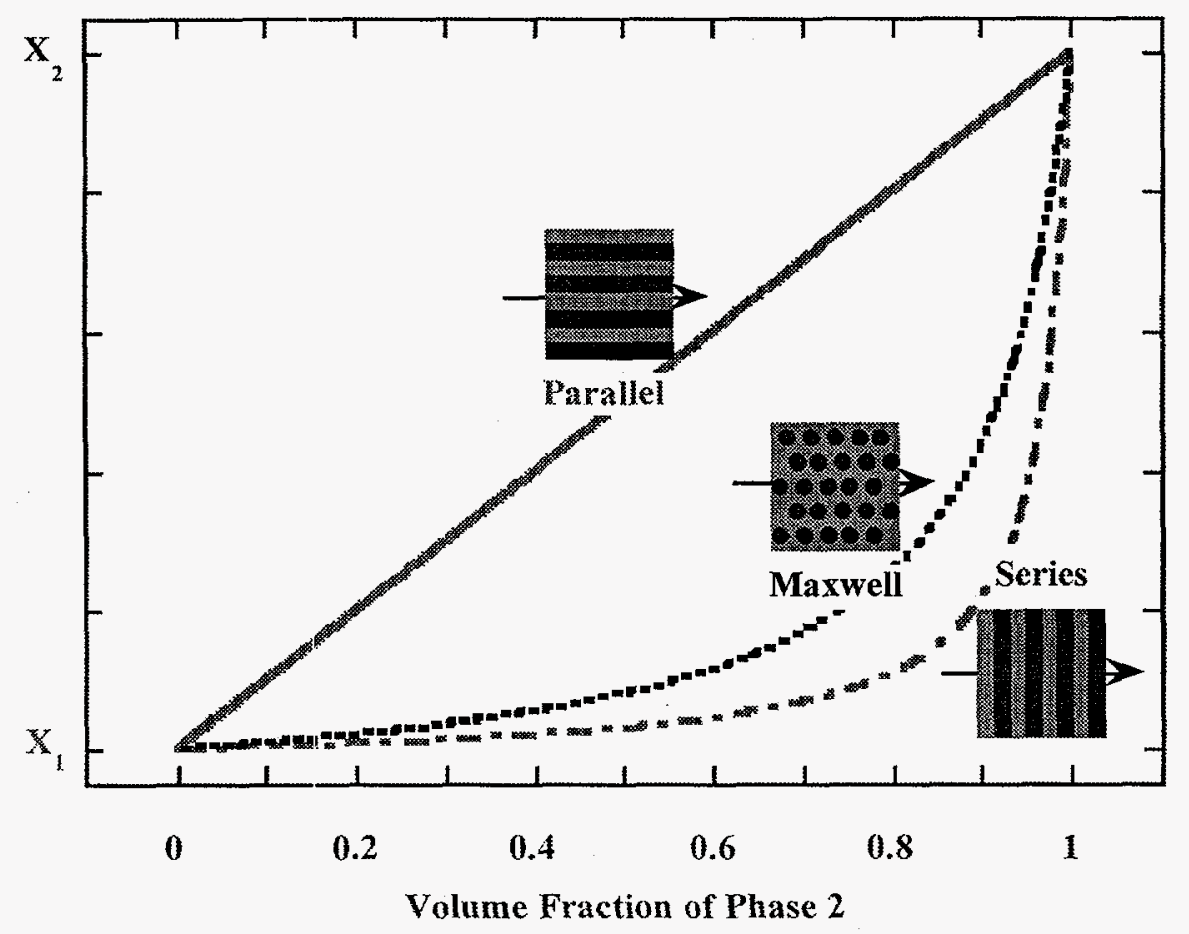

Figure 5. A comparison of Parallel, Series, and Maxwell Mixing Model predictions for a two-phase composite. Parallel and Series Model predictions bound the sum properties of a two-phase composite, while the Maxwell Model predicts properties intermediate to those extremes.

\section{DESIGNING CFG COMPOSITE DIELECTRICS}

A high ceramic filler concentration affords the greatest latitude in controlling the composition, and ultimately, the properties of a CFG composite; however, excessively high filler concentrations can severely inhibit densification. A low viscosity glass is required to ensure good CFG composite densification with a high ceramic filler concentration (Figure 1); therefore, a low viscosity glass is also required to achieve the greatest latitude to tailor composite properties such as dielectric constant, coefficient of thermal expansion, and thermal conductivity. 


\section{Glasses for CFG Composite Dielectrics}

Commercial $\mathrm{CFG}$ composite dielectrics often employ $\mathrm{SiO}_{2}$-based glasses as the sintering flux and inorganic binder [10-13]. These glasses typically have moderate to high wetting angles on oxide ceramics, and high viscosities at $800-1000^{\circ} \mathrm{C}[20]$; consequently, to ensure good CFG composite densification at $\leq 1000^{\circ} \mathrm{C}$, most commercial systems are limited to $\leq 30 \%$ ceramic filler phase [10-13].

Improved $\mathrm{CFG}$ composites for microelectronics packaging may be produced by substituting $\mathrm{B}_{2} \mathrm{O}_{3}$-based glass for $\mathrm{SiO}_{2}$-based glasses. $\mathrm{B}_{2} \mathrm{O}_{3}$-based glasses offer good wetting and low viscosities at $800-1000^{\circ} \mathrm{C}[14,19,20]$, which should favor higher ceramic filler concentrations. Additionally, $\mathrm{B}_{2} \mathrm{O}_{3}$-based glasses have high electrical resistivities, low dielectric constants and losses, and low thermal expansion coefficients, which are desirable for microelectronics packaging $[19,20]$.

\section{Ceramic Fillers for CFG Composite Dielectrics}

Alumina is the ceramic filler of choice in conventional CFG composite dielectrics [10-13]; however, silicate ceramics also possess some appealing characteristics as filler materials. For example, quartz and fused silica are low dielectric constant materials that offer a range of expansion coefficients (e.g., for greater CFG composite design flexibility) $[14,19]$.

\section{EXPERIMENTAL PROCEDURE}

To evaluate the process and property models discussed in this paper, and to assess the applicability of the integrated concepts presented to design and manufacture tailored property composite dielectrics for microelectronics packaging, alumina and silicate-ceramic-filled, $\mathrm{B}_{2} \mathrm{O}_{3}$-based glass composites were designed, fabricated, and characterized.

\section{Preparing $\mathrm{B}_{2} \mathrm{O}_{3}$-Based Glasses}

$\mathrm{B}_{2} \mathrm{O}_{3}$-based glasses for $\mathrm{CFG}$ composite dielectrics were prepared using conventional glass melting techniques, whereby the respective glass precursors (e.g., nitrates, acetates, carbonates, and/or oxides) were mixed together and reacted in a platinum crucible at $1000-1100^{\circ} \mathrm{C}$ in air for $\leq 1 \mathrm{hr}$. The glass melt was fritted by quenching in water, followed by drying, and then milling to produce a narrow size distribution of particles about a median particle size range of 1.0-10.0 $\mu \mathrm{m}$. The properties of the $\mathrm{B}_{2} \mathrm{O}_{3}$-based glasses produced were characterized using standard methods described in previous work [20]. The glass compositions prepared, and their properties are summarized in Table 4. 
Table 4. $\mathrm{B}_{2} \mathrm{O}_{3}$-Based Glass Compositions for CFG Composite Dielectrics, and Their Properties

\begin{tabular}{|c|c|c|c|}
\hline Property & AEAB & AEASB 5 & AEASB 15 \\
\hline $\begin{array}{l}\text { Composition (Mole \%) } \\
\mathrm{SiO}_{2} \\
\mathrm{~B}_{2} \mathrm{O}_{3} \\
\mathrm{Al}_{2} \mathrm{O}_{3} \\
\mathrm{CaO} \\
\mathrm{BaO}\end{array}$ & $\begin{array}{c}0 \\
60 \\
10 \\
10 \\
20\end{array}$ & $\begin{array}{c}5 \\
55 \\
10 \\
10 \\
20\end{array}$ & $\begin{array}{l}15 \\
45 \\
10 \\
10 \\
20\end{array}$ \\
\hline Density (g/cc) & 3.08 & & \\
\hline $\begin{array}{l}\text { Coefficient of Thermal Expansion } \\
\text { RT-300 }{ }^{\circ} \mathrm{C}\left(\mu \mathrm{m} / \mathrm{m} /{ }^{\circ} \mathrm{C}\right)\end{array}$ & 6.57 & 5.06 & 5.57 \\
\hline $\begin{array}{l}\text { Glass Transition } \\
\text { Temperature }\left({ }^{\circ} \mathrm{C}\right)\end{array}$ & 588 & 591 & 587 \\
\hline $\begin{array}{l}\text { Dilatometric Softening } \\
\text { Temperature }\left({ }^{\circ} \mathrm{C}\right)\end{array}$ & 631 & 635 & 645 \\
\hline $\begin{array}{l}\text { Wetting Angle on } \mathrm{Al}_{2} \mathrm{O}_{3}\left(^{\circ}\right) \\
900^{\circ} \mathrm{C} \\
750^{\circ} \mathrm{C} \\
\end{array}$ & $\begin{array}{c}<5 \\
0 \\
\end{array}$ & $\begin{array}{c}5 \\
41 \\
\end{array}$ & $\begin{array}{c}5 \\
45 \\
\end{array}$ \\
\hline $\begin{array}{l}\text { Glass Surface Tension }\left(\mathrm{J} / \mathrm{m}^{2}\right) \\
900^{\circ} \mathrm{C} \\
750^{\circ} \mathrm{C} \\
\end{array}$ & 0.3 & $\begin{array}{l}0.34 \\
0.37\end{array}$ & $\begin{array}{l}0.44 \\
0.47\end{array}$ \\
\hline $\begin{array}{l}\text { Glass Viscosity (Pa・s): } \\
900^{\circ} \mathrm{C} \\
750^{\circ} \mathrm{C}\end{array}$ & $\begin{array}{l}10^{1.0} \\
10^{3.5}\end{array}$ & $\begin{array}{l}10^{1.5} \\
10^{5.5}\end{array}$ & $\begin{array}{l}10^{2.0} \\
10^{6.5}\end{array}$ \\
\hline
\end{tabular}

Fabricating CFG Composites

CFG composites were produced by dispersing the requisite amounts of ceramic filler(s) and glass in isopropyl alcohol, and Spex $®$ milling. Disc-shaped CFG composite bodies were formed by uniaxal die pressing the dried powder mixture at $\leq 650 \mathrm{MPa}$ in a stainless steel die. Dense CFG composites were produced by sintering or hot pressing at $2-50^{\circ} \mathrm{C} / \mathrm{min}$. to $800-1000^{\circ} \mathrm{C}$, soaking for $0.17-2 \mathrm{hr}$ in air or argon, and cooling to room temperature at $<50^{\circ} \mathrm{C} / \mathrm{min}$. 


\section{Characterizing CFG Composites}

To test the ability of the NLPS model to predict CFG composite densification, and the ability of the sum-property models to predict $\mathrm{CFG}$ composite dielectric constant, thermal expansion, and thermal conductivity, CFG composites were designed and fabricated with an in-house $\mathrm{B}_{2} \mathrm{O}_{3}$-based glass (AEAB) filled with A152sg alumina (ALCOA; Pittsburgh, PA), quartz (DuPont; Wilmington, DE), Silica (Sigma Chemical Co.; St. Louis, MO), or mixtures of quartz and silica. The composite properties characterized, the models evaluated, and the composite compositions examined are summarized in Table 5.

Table 5. The Composite Properties, Models, and Compositions Evaluated

\begin{tabular}{|c|c|c|}
\hline Property & Model & Composite Composition \\
\hline Densification & Final-Stage NLPS & $\begin{array}{c}50 \text { Vol.\% Alumina } \\
+ \\
\text { AEAB Glass } \\
\end{array}$ \\
\hline Dielectric Constant & Maxwell Mixing & $\begin{array}{c}0-50 \text { Vol.\% Alumina } \\
+ \\
\text { AEAB Glass }\end{array}$ \\
\hline Thermal Expansion & Parallel Mixing & $\begin{array}{c}\text { 0-70 Vol.\% Quartz and } \\
\begin{array}{c}70-0 \text { Vol.\% Silica } \\
+\end{array} \\
\text { 30 Vol.\% AEAB Glass } \\
\end{array}$ \\
\hline Thermal Conductivity & Maxwell Mixing & $\begin{array}{c}0-65 \text { Vol.\% Alumina } \\
+ \\
\text { AEAB Glass }\end{array}$ \\
\hline
\end{tabular}

Composite linear shrinkage during sintering was measured as a function of time at 800 and $900^{\circ} \mathrm{C}$ using a thermomechanical analyzer (DuPont; Wilmington, DE). Assuming isotropic densification, the measured linear shrinkage was converted to a relative sintered density, $\rho_{\mathrm{S}}$, using the expression [34];

$$
\rho_{\mathrm{s}}=\frac{\rho_{\mathrm{g}}}{(1-\Delta \mathrm{L} / \mathrm{L})^{3}}
$$


where, $\rho_{g}$ is the original (green) density of the sample, $\mathrm{L}$ is the original length of the sample, and $\Delta \mathrm{L}$ is the change in length with time during sintering. Composite dielectric constant was determined from capacitance measurements made over a range of $100 \mathrm{~Hz}$ to $10 \mathrm{MHz}$ using a complex impedance bridge (Hewlett Packard; Palo Alto, CA). Composite linear coefficient of thermal expansion was measured from room temperature to $300^{\circ} \mathrm{C}$ using a thermomechanical analyzer. Composite thermal conductivity was determined from the composite density measured by helium pycnometry (Micromeretics; Norcross GA), the composite heat capacity measured by differential scanning calorimetry (DuPont; Wilmington, DE), and the composite diffusivity measure by the laser flash technique [17-18].

\section{RESULTS AND DISCUSSION}

\section{CFG Composite Sintering}

The measured CFG composite densification with time at 800 and $900^{\circ} \mathrm{C}$ is compared to final-stage NLPS model predictions (Equation 2) in Figure 7. Model predictions and experimental results are in good agreement, demonstrating the ability of the NLPS model to predict alumina-filled AEAB glass composite densification during sintering. Although not yet fully tested, it is expected that the NLPS model will be generally applicable to CFG composites that do not violate the model assumptions detailed in Table $3 \mathrm{a}$.

In addition to the obvious advantages of being able to predict CFG composite densification, the validation of the NLPS sintering model provides credibility for using sintering maps such as Figure 1 to guide CFG composite design and processing. For example, the sintering map presented in Figure 1 shows that ceramic filler concentrations in excess of the $30 \%$ (by volume) typically used in commercial systems [10-13] are possible with low viscosity glasses. In turn, higher ceramic filler concentrations would provide significantly more latitude to design tailored-property CFG composites.

\section{CFG Composite Dielectric Properties}

Measured $1 \mathrm{Mhz}$ dielectric constants of alumina-filled AEAB glass composites containing up to $50 \%$ by volume alumina are compared to Parallel, Maxwell, and Series Mixing Model predictions in Figure 7. Measured dielectric constants for composites containing $\geq 20 \%$ alumina fall below the predictions of the Series Model, which should define the lower bound for the composite. This unexpected result is attributed to the residual porosity believed to be present in the aluminafilled glass composites examined. The influence of porosity on lowering dielectric 


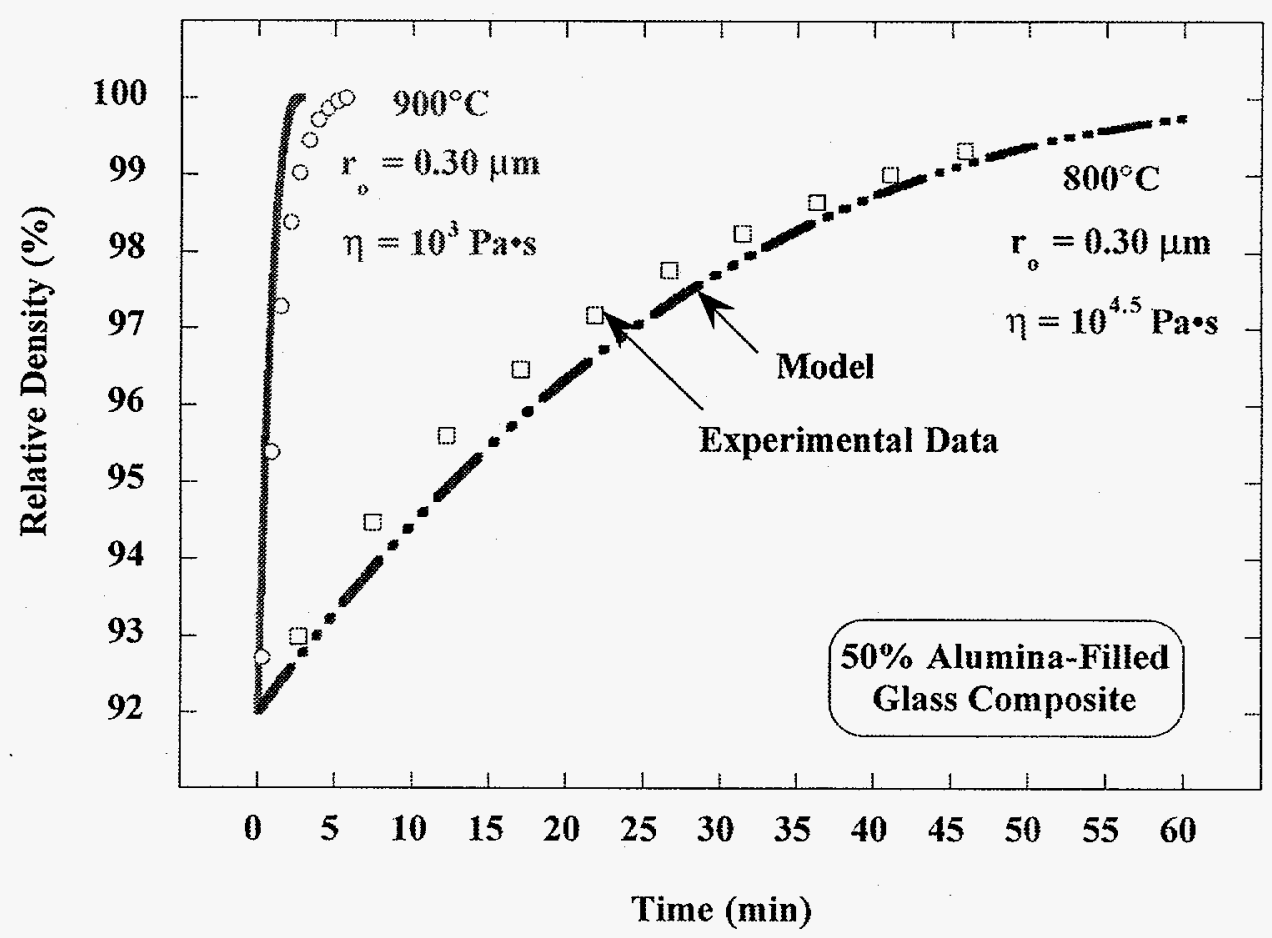

Figure 6. Final-stage densification of a $50 \%$ by volume alumina-filled $\mathrm{AEAB}$ glass composite at $800^{\circ} \mathrm{C}$ (circles) and $900^{\circ} \mathrm{C}$ (squares) in comparison to NLPS model predictions (Equation 2). Values of $\eta=10^{3}$ and $10^{4.5} \mathrm{~Pa} \cdot \mathrm{s}$ at 900 and $800^{\circ} \mathrm{C}$, respectively, and $\mathrm{r}_{\mathrm{o}}=0.30 \mu \mathrm{m}$ were used in the model calculations.

constant is well documented [15,29], and indicates that the lowest dielectric constant $\mathrm{CFG}$ composite will be produced with a low dielectric constant filler.

Despite the lower than expected dielectric constants measured, the absolute difference between the model predictions and the measured values are relatively small (i.e., $\sim 0.5$ ). Also, in spite of vastly different geometries, all three models predict similar results. The small differences observed are attributed to the fact that the absolute difference in magnitude between the dielectric constant of pure $\mathrm{AEAB}$ glass (7.8) and pure alumina (10.5) is also relatively small [16]. Therefore, 


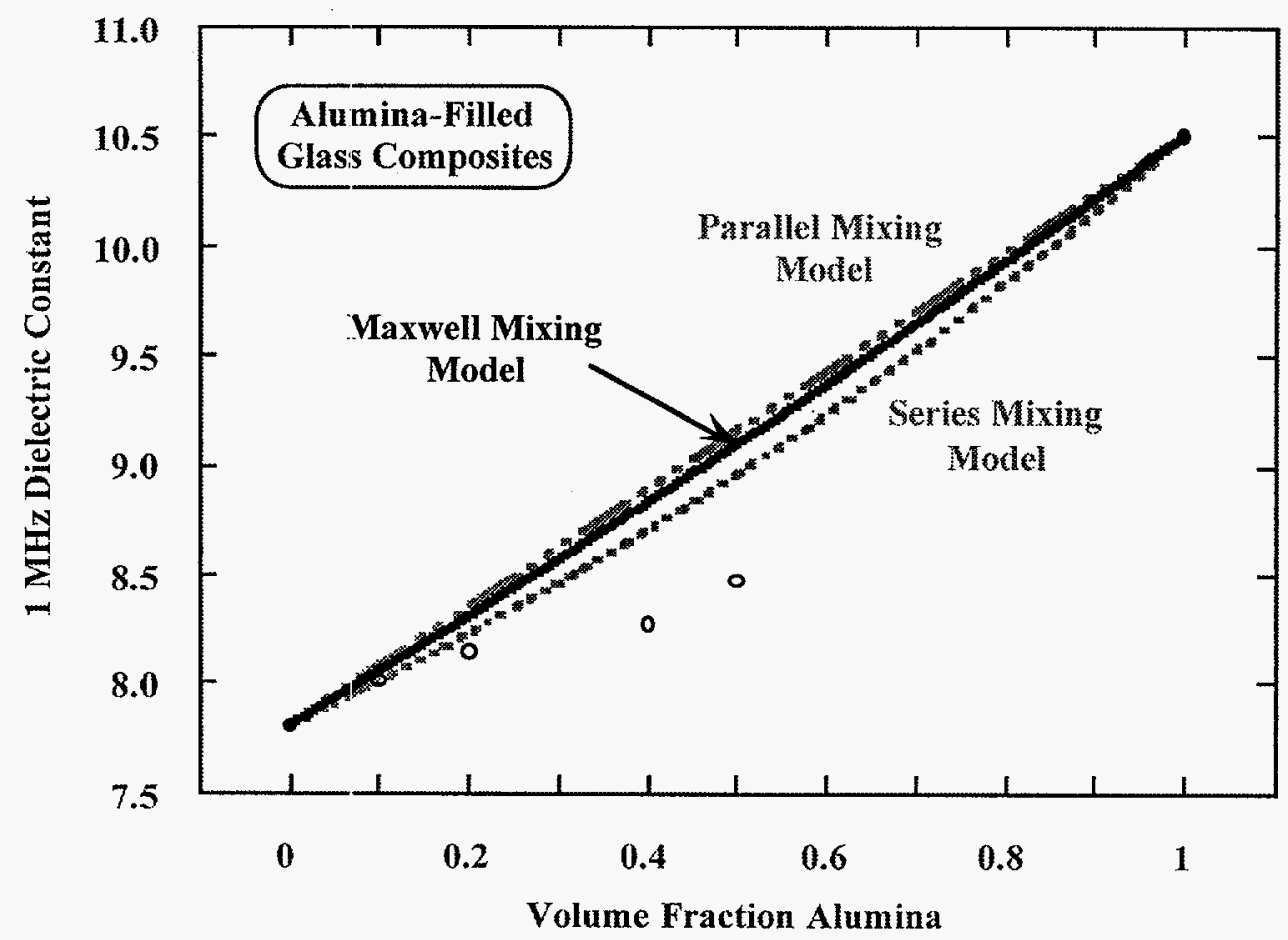

Figure 7. Measured alumina-filled AEAB glass composite dielectric constant at $1 \mathrm{MHz}$ (circles) compared to Parallel, Series, and Maxwell Model predictions.

while Maxwell Model predictions should best agree with measured values of CFG composite dielectric constant [29,31], for small differences between the absolute magnitudes of the dielectric constants of the composite constituents, any of the models should yield an acceptable approximation.

\section{CFG Composite Coefficient of Thermal Expansion}

Thermal expansion coefficients for silica and/or quartz-filled AEAB glass composites containing $30 \%$ by volume glass are plotted in comparison with Parallel Mixing Model predictions in Figure 8. The pure silica-filled glass composite has the lowest expansion, and expansion increases with the substitution of quartz for silica. Based on the measured thermal expansions of the 


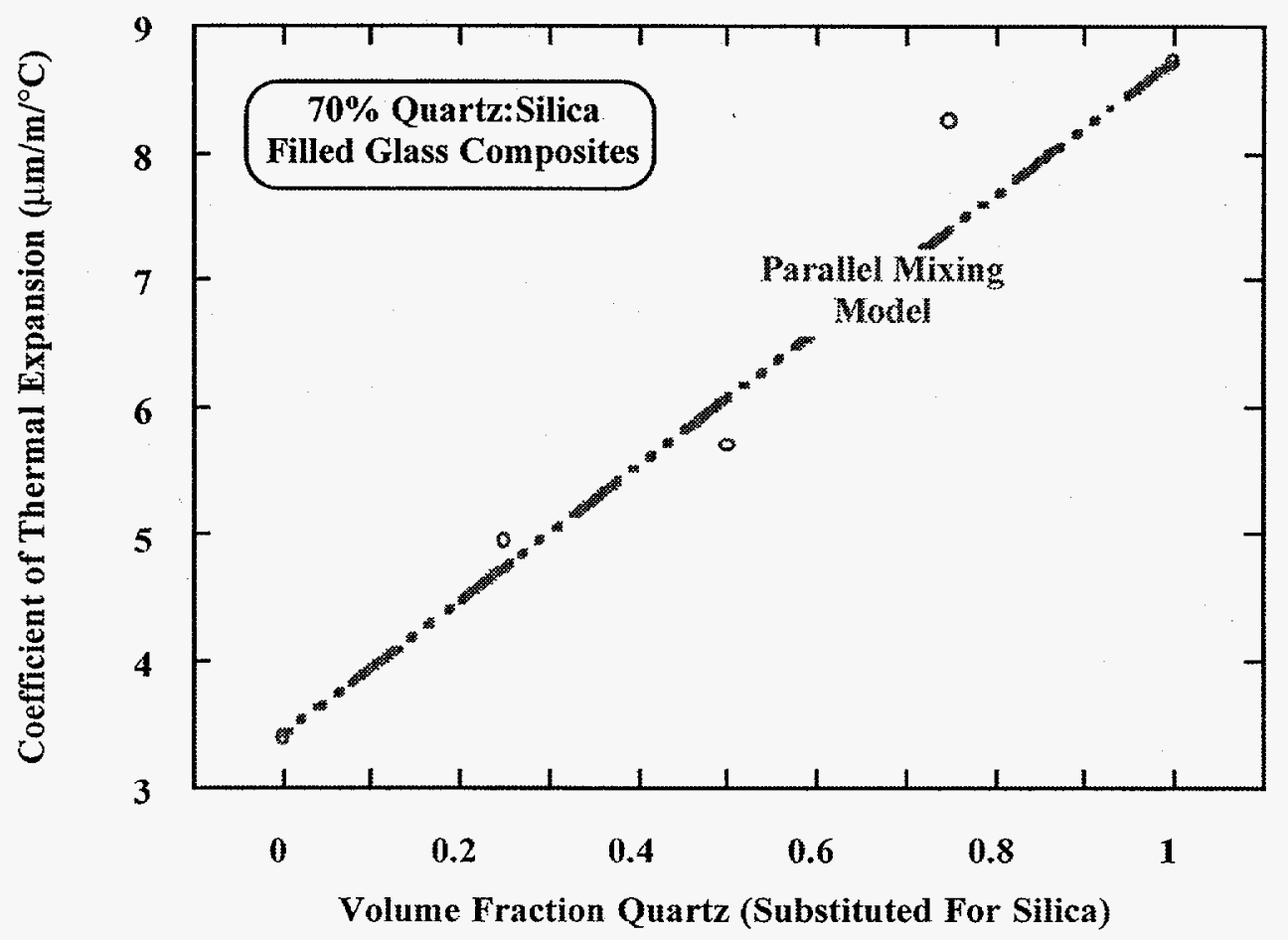

Figure 8. Measured thermal expansion of $70 \%$ by volume quartz and/or silica-filled AEAB glass composites (circles) compared to Parallel Mixing Model predictions.

end members, the Parallel Mixing Model predictions agree reasonably well with the measured values.

The results presented in Figure 8 demonstrate that, with sufficient filler concentration, and an appropriate mixture of low and high expansion fillers, the expansion of a CFG composite can be tailored to match the expansion coefficient of Si $\left(\sim 3.5 \mu \mathrm{m} / \mathrm{m} /{ }^{\circ} \mathrm{C}\right)$ or alumina $\left(\sim 6.7 \mu \mathrm{m} / \mathrm{m} /{ }^{\circ} \mathrm{C}\right)$. Furthermore, because of the inherent compatibility in the glass composite system, it also would be possible to design and fabricate a functionally graded material that provides an expansion match to both silicon and alumina. This provides even greater design latitude for CFG composites. 


\section{CFG Composite Thermal Conductivity}

Thermal conductivities of alumina-filled $\mathrm{AEAB}$ glass composites containing up to $65 \%$ by volume alumina are compared to Maxwell Model predictions in Figure 9. Published thermal conductivities for higher alumina concentrations ranging from 86-99\% are also plotted [33]. The Maxwell Model predictions are in very good agreement with measured and reported composite thermal conductivities.

The information presented in Figure 9 clearly demonstrates that the thermal conductivity of a $\mathrm{CFG}$ composite can be improved by adding a higher thermal conductivity ceramic filler to a lower conductivity glass. Additionally, higher filler concentrations yield higher composite thermal conductivities. To achieve the highest thermal conductivity without sacrificing processability, a CFG glass composite can be filled with up to $50 \%$ of a high thermal conductivity filler.

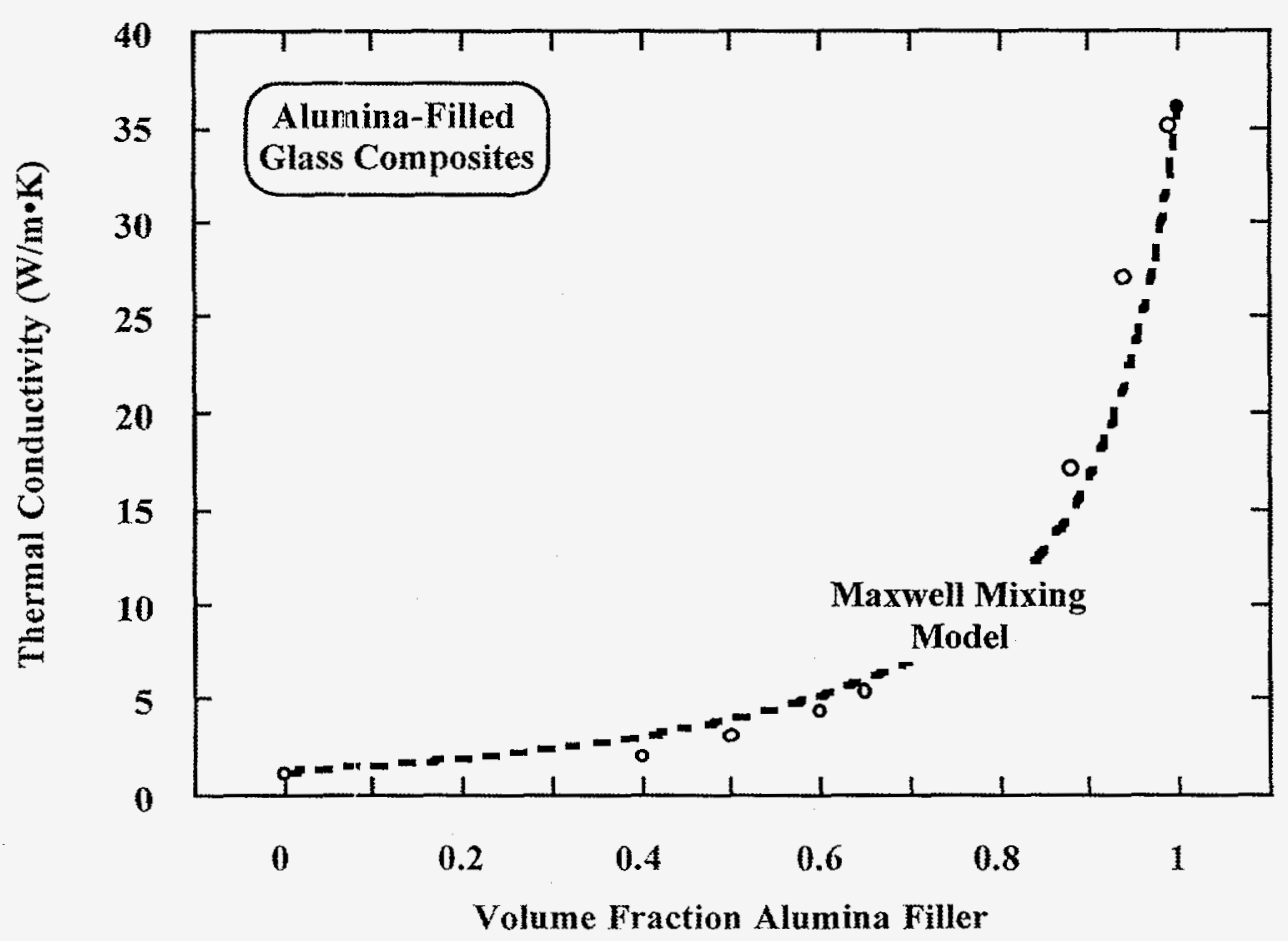

Figure 9. Measured values alumina-filled AEAB glass composite thermal conductivity (circles) compared to Maxwell Mixing Model predictions. 


\section{SUMMARY}

Ceramic-filled glass (CFG) composites densify by viscous flow during final-stage sintering, and densification depends on a critical relationship between the ceramic filler concentration, glass viscosity, and CFG composite dispersion viscosity. A mathematical expression developed to describe final-stage sintering reveals that CFG composite densification can be controlled by controlling filler concentration, sintering time, pore size, and glass viscosity. Using this mathematical expression, sintering maps have been constructed that provide design and process guidelines for manufacturing CFG composites. The sintering maps define the practical limits of ceramic filler concentration that can be used to design and manufacture processable CFG composites

In conjunction with the sintering theory and sintering maps for CFG composites, sum-property models can be used to design application-tailored CFG composites. Based on the properties of the constituent phases and their relative concentrations, the Parallel Model can be used to predict CFG composite coefficient of thermal expansion, and the Maxwell Mixing Model can be used to predict CFG composite dielectric constant and thermal conductivity.

Alumina and silicate-filled, $\mathrm{B}_{2} \mathrm{O}_{3}$-based glass composites offer a appealing alternative to the ceramic-filled, $\mathrm{SiO}_{2}$-based glass composites currently used in microelectronics packaging, as they are low-temperature-sintering, CFG composite dielectrics with improved dielectric, thermal, and mechanical properties. Additionally, the properties of ceramic-filled, $\mathrm{B}_{2} \mathrm{O}_{3}$-based glass composites can be tailored to meet the specific performance requirements of a broad range of microelectronics packaging applications. The range of composite properties achieved in alumina and silicate-filled $\mathrm{B}_{2} \mathrm{O}_{3}$-based glass composites by employing the process and property model relations discussed in this paper are summarized in Table 5.

Table 6. Material Properties Obtained by Employing Process and Property Model Relations To Design CFG Composite Dielectrics

\begin{tabular}{|l|c|}
\hline \multicolumn{1}{|c|}{ Property } & Magnitude \\
\hline Dielectric Constant $@ \mathbf{~} \mathbf{1 0 0} \mathbf{~ k H z}$ & $4.5-9.0$ \\
\hline Coefficient of Thermal Expansion $\left(\mu \mathrm{m} / \mathbf{m} /{ }^{\circ} \mathbf{C}\right)$ & $3.5-9.0$ \\
\hline Thermal Conductivity $(\mathbf{W} / \mathbf{m} \cdot \mathbf{K})$ & $1.0-7.5$ \\
\hline
\end{tabular}




\section{ACKNOWLEDGMENTS}

This work was supported by the U. S. Department of Energy under contract No. DE-AC04-94AL85000 at Sandia National Laboratories. This work was also supported by the E. I. du Pont de Nemours \& Company Central Research Department. Thanks go to Michael Ready and Ronald E. Loehman for providing a critical review of this manuscript.

\section{REFERENCES}

1) "Administrator's Budget Request Boosts Funding for Advanced Materials and Processing," Bull. Am Ceram. Soc., 71 [3] 248-9 (1992).

2) R. R. Tummala, "Ceramics in Microelectronic Packaging," Bull. Am Ceram. Soc., 67 [4] 752-8 (1988).

3) R. W. Rice, J. H. Enloe, J. W. Lau, E. Y. Luh, and L. E. Dolhert, "Hot pressing - A New Route to High-Performance Ceramic Multilayer Electronic Packages," Bull Am. Ceram Soc., 71 [5] 751-55 (1992).

4) W. D. Kingery, "Densification During Sintering in the Presence of a Liquid Phase. I. Theory," J. Appl. Phys., 30 [3] 301-306 (1959).

5) F. V. Lenel, Powder Metallurgy, Principles and Applications, Metal Powder Industries Federation, Princeton, NJ, 1980 pp. 285-307.

6) R. M. German, Liquid Phase Sintering, Plenum Press, New York, 1985.

7) W. D. Kingery, H. K. Bowen, and D. R. Uhlmann, Introduction to Ceramics, Second edition, John Wiley \& Sons, New York, NY, 1976, pp. 448-515.

8) C. A. Jouenne, "Sintering of a Solid Phase Plus Vitreous Phase Combination: Case of Faience, Sandstone, and Porcelain," Ind. Ceram., [613] 951-64 December (1968).

9) S. Pejovnik, D. Kolar, W. J. Huppman, and G. Petzow, "Sintering of Alumina in Presence of Liquid Phase," pp. 285-292 in Sintering - New Developments, Materials Science Monographs 4, Elsevier Science Publishing Co., Inc., New York, NY, 1979.

10) Y. Shimada, K. Utsumi, M. Suzuki, H. Takamizawa, M. Nitta, and S. Yano, "Low Firing Temperature Multilayer Glass-Ceramic Substrate," pp. 314319 in the Proc. 33rd Electron. Compon. Conf. The Institute of Electrical and Electronics Engineers, Inc., New York, NY, 1983.

11) W. A. Vitriol and J. I. Steinberg, "Development of Low Temperature Cofire Multilayer Ceramic Technology," Int. J. Hybrid Microelectron., 6 [1] 593598 (1983).

12) S. Nishigaki, S. Yano, J. Fukuta, M. Fukaya, and T. Fuwa, "A New Multilayered, Low-Temperature-Fireable Ceramic Substrate," pp. 225-234 
in the Proc. 1985 Intl. Symposium on Microelectronics, The International Society for Hybrid Microelectronics, Reston, VA, 1985.

13) J. I. Steinberg, S. J. Horowitz, and R. J. Bacher, "Low Temperature Tape Dielectric Material Systems for Multilayer Interconnections," Solid State Technol., 97-101 (1986).

14) D. M. Mattox, S. R. Gurkovich, J. A. Olenick, and K. M. Mason, "LowDielectric-Constant, Alumina-Compatible, Co-Fired, Multilayer Substrate," pp. 431-43 in Ceramic Substrates and Packages for Electronic Applications, Advances in Ceramics Vol 26, M. F. Yan, K. Niwa, H. M. O'Bryan, Jr., and W. S. Young, editors, The American Ceramic Society, Inc., Westerville, $\mathrm{OH}$, 1987.

15) M. J. Leap, W. Huebner, and I. Eicher, "Low-Permittivity Silica, HollowGlass-Microsphere 0-3 Composites," pp. 399-407 in Ceramic Substrates and Packages for Electronic Applications, Advances in Ceramics Vol 26, M. F. Yan, K. Niwa, H. M. O'Bryan, Jr., and W. S. Young, editors, The American Ceramic Society, Inc., Westerville, OH, 1987.

16) R. M. Anderson, R. Gerhardt, and J. B. Wachtman, Jr., "Thermal, Mechanical, and Dielectric Properties of Mullite-Cordierite Composites," pp. 265-277 in Ceramic Substrates and Packages for Electronic Applications, Advances in Ceramics Vol 26, M. F. Yan, K. Niwa, H. M. O'Bryan Jr., and W. S. Young, editors, The American Ceramic Society, Inc., Westerville. OH, 1987.

17) M. L. Allit, A. J. Whittaker, D. G. Onn, and K. G. Ewsuk, "A Study of the Thermal Conductivity of Alumina/Glass Dispersed Composites," Intl. $J$. Thermophysics, 10 [5] 1053-62 (1989).

18) Kevin G. Ewsuk, "Thermal Conductivity of Glass-Filled Ceramic Composites," Report CRD-87-25, E. I. du Pont de Nemours \& Co., Inc., (1987).

19) N. Ushifusa and S. Ogihara, "Multilayer Ceramic Circuit Board," United States Patent No. 4,598,167 (1986).

20) K. G. Ewsuk, L. W. Harrison, and F. J. Walczak, "Sintering of Glass-Filled Ceramic Composites; Effects of Glass Properties," pp. 969-77 in Ceramic Powder Science II, Part B, Ceramic Transactions Vol. 1, G. L. Messing, E. R. Fuller, and H. Hausner, editors, The American Ceramic Society, Inc., Westerville, $\mathrm{OH}, 1988$.

21) K. G. Ewsuk and L. W. Harrison, "Densification of Glass-Filled, Alumina Composites," pp. 436-51 in Sintering of Advanced Ceramics, Ceramic Transactions Vol. 7, C. Handwerker, J. Blendell, and W. A. Kaysser, editors, The American Ceramic Society, Inc., Westerville, OH, 1990

22) K. G. Ewsuk, "Effect of Filler Loading on Final-Stage Viscous Sintering of Ceramic-Filled-Glass Composites," pp. 747-54 in Ceramic Powder 
Processing Science. H. Hausner, G. L. Messing, and S. Hirano., editors, Deutsche Keramische Gesellschaft, Köln, FRG, 1989.

23) A. J. Shaler, "Seminar on Kinetics of Sintering" (with discussion), J. Met., 1 [11] 796-813 (1949).

24) K. G. Ewsuk, "Ceramic-Filled-Glass Composite Sintering," pp. 279-95 in Materials and Processes for Microelectronic Systems, Ceramic Transactions Vol. 15, K. M. Nair, R. Pohanka and R. C. Buchanan, editors, The American Ceramic Society, Westerville, OH, 1990.

25) K. G. Ewsuk, "Sintering Maps for Ceramic-Filled-Glass Composites," pp. 125-35 in Ceramic Transactions Vol 19, Advanced Composite Materials: Processing, Microstructure, Bulk and Interfacial Characterization, Characterization Methods, and Applications, edited by Michael D. Sacks, The American Ceramic Society, Westerville, OH, 1991.

26) K. G. Ewsuk, "Effects of Trapped Gases on Ceramic-Filled-Glass Composite Densification," pp. 63-72 in Solid State Phenomena Vol 25-26, Sintering' 91, edited by A. C. D. Chaklader and J. A. Lund, Trans. Tech Publications Ltd., Brookfield, VT, 1992.

27) H. Eilers, "The Viscosity of Emulsions of Highly Viscous Materials as a Function of Concentration," Kolloid-ZZ Polym., 97, 313-21 (1941).

28) L. H. Van Vlack, Elements of Materials Science and Engineering, third edition, Addison-Wesley Publishing Co., Massachusetts, 1975, pp. 349359.

29) W. D. Kingery, H. K. Bowen, and D. R. Uhlmann, Introduction to Ceramics, John Wiley \& Sons, New York, 1976, pp. 947-951.

30) R. C. Pohanka and P. L. Smith, "Recent Advances in Piezoelectric Ceramics," pp. 45-145 in Electronic Ceramics, Properties, Devices, and Applications, L. M. Levinson, editor, Marcel Dekker, Inc. New York, 1988.

31) G. Goodman, "Ceramic Capacitor Materials," pp. 79-138 in Ceramics For Electronics, Processing, Properties, and Applications, R. C. Buchanan, editor, Marcel Dekker, Inc. New York, 1986.

32) D. P. Button, B. A. Yost, R. H, French, W. Y. Hsu, J. D. Bolt, H. M. Zhang, R. E. Giedd, A. J. Whittaker, and D. G. Onn, "CeramicFiber/Polymer Laminates: Thermally Conductive Composites with Low Dielectric Constants," pp. 353-373 in Ceramic Substrates and Packages for Electronic Applications, Advances in Ceramics Vol 26, M. F. Yan, K. Niwa, H. M. O'Bryan Ir., and W. S. Young, editors, The American Ceramic Society, Inc., Westerville, OH, 1987.

33) E. Dorre and H. Hubner, Alumina, Processing, Properties, and Applications, B. Ilshner and N. J. Grant editors, Springer-Verlag, Berlin, Heidleberg, 1984. pp. 11-15. 
34) K. G. Ewsuk and L. W. Harrison, "Filler Particle Size and Size Distribution Effects on Ceramic-Filled-Glass Composite Sintering," pp. 639-48 in Ceramic Powder Science III, Ceramic Transactions Vol 12, G. L. Messing, S. Hirano, and H. Hausner, editors, The American Ceramic Society, Inc., Westerville, OH, 1990. 